\title{
Rapazes negros e socialização de gênero: \\ sentidos e significados de "ser homem"*
}

Raquel Souza**

\begin{abstract}
Resumo
Este artigo discute os processos de socialização de rapazes negros $e$ pobres da cidade de São Paulo, problematizando como determinados sentidos e experiências sobre a masculinidade são construídos e reelaborados em suas trajetórias. A partir de trabalho empírico realizado entre 2007 e 2008, argumentamos em torno da ideia de que a masculinidade é uma experiência que permeia a trajetória dos sujeitos, nunca acabada e marcada por revezes.
\end{abstract}

Palavras-chave: Juventude, Rapazes Negros, Socialização, Masculinidade.

\footnotetext{
" Recebido para publicação em março de 2010, aceito em maio de 2010. Agradecimentos especiais às professoras da Faculdade de Educação da USP Marilia Pinto de Carvalho e Marilia Pontes Sposito, por seus comentários e sugestões.

** Mestre em Sociologia da Educação pela Faculdade de Educação da USP. Assessora da ONG Ação Educativa - Assessoria, Pesquisa e Informação e integrante do Grupo de Estudos em Temas da Sociologia da Educação (GETESE-FE-USP).raquel@acaoeducativa.org
}

cadernos pagu (34), janeiro-junho de 2010:107-142. 
Rapazes negros e socialização de gênero

Afro Descendant Boys and Gender Socialization:

Meanings of "Being a Man"

\begin{abstract}
This paper discusses the processes of socialization of young black and poor boys in the city of São Paulo, questioning how certain meanings and experiences of masculinity are constructed and reworked in their lives. From empirical research conducted between 2007 and 2008, we base our paper on the idea that masculinity is an experience that penetrates the trajectory of individuals, never finished and marked by setbacks.
\end{abstract}

Key Words: Youth, Black Boys, Socialization, Masculinity. 
Olhar para a juventude e os modos de vida daqueles que se encontram nessa condição tem se constituído em uma forma profícua para compreender as mutações que se operam no mundo contemporâneo. Sem negar que elas atingem todos os grupos sociais, independentemente da etapa de vida em que se encontram, há certo consenso de que as mudanças socioculturais influenciam, sobretudo, as subjetividades daqueles que se defrontam com o desafio de se posicionar em um contexto de incertezas, novidades e intensas transformações sociais, culturais, econômicas e políticas. Velhos e novos aprendem juntos a viver em uma sociedade cada vez mais atualizada $e$ indeterminada. Contudo,

Enquanto o adulto vive ainda sob o impacto de um modelo de sociedade que se decompõe, o jovem já vive em um mundo radicalmente novo, cujas categorias de inteligibilidade ele ajuda a construir. Interrogar essas categorias permite não somente uma melhor compreensão do universo de referências de um grupo etário particular, mas também da nova sociedade transformada pela mutação (Peralva, 1997:23).

No que diz respeito às relações de gênero e à constituição de subjetividades dos brasileiros, análises recentes têm apontado que transformações sociais contemporâneas de diversas ordens imprimiram fortes alterações na esfera dos costumes, ainda que não se possa afirmar de maneira alguma o fim dos desequilíbrios e desigualdades. Esse fenômeno articula-se com uma série de mudanças que incluem a redução do tamanho da família, o prolongamento $e$ a difusão maciça da escolarização, a intensa urbanização do país, o amplo crescimento da comunicação de massa, a diversificação da cena religiosa, o surgimento do feminismo e do movimento por direitos civis de homossexuais. Paralelamente, estudiosos atestam a existência de uma expansão dos ideais igualitários de relação entre os sexos que conduz a uma relativa diminuição do contraste entre as experiências femininas $e$ 
Rapazes negros e socialização de gênero

masculinas, por exemplo, no que concerne ao acesso à escolarização e ao emprego (Heilborn, Cabral e Bozón, 2006).

Nesse contexto, entender como os jovens significam as relações de gênero e atribuem sentidos à masculinidade e à feminilidade pode se constituir em um exercício para verificar fraturas $e$ (des)continuidades nos significados socialmente disponíveis, manipulados e/ou construídos pela juventude para forjar suas experiências e valores. Todavia, num recente balanço sobre a produção acadêmica do tema "Juventude" no interior da Pós-Graduação - nas áreas de Ciências Sociais, Educação e Serviço Social -, um levantamento coordenado por Sposito (2009) identificou 1.427 teses e dissertações, produzidas entre 1999 e 2006, mas apenas 133 foram agrupadas no subitem denominado "Jovens, sexualidade e gênero" (9,32\% do total de produções).

A análise dos trabalhos permitiu constatar um predomínio de estudos voltados a questões atinentes à educação sexual dos jovens, aos comportamentos referentes ao exercício da sexualidade e à compreensão de aspectos que permeiam a assunção da gravidez na adolescência. Apenas 33 trabalhos abordavam questões sobre masculinidades e feminilidades, compondo um grupo marcado pela heterogeneidade e dispersão, sem se conformar, por isso, em torno de questões ou problemáticas comuns (Carvalho, Souza e Oliveira, 2009). Outros aspectos relevantes sobre os estudos foram: a predominância de pesquisas sobre moças e, secundariamente, rapazes pobres (em especial aqueles envolvidos com atos violentos ou ilícitos). De maneira geral, estes eram caracterizados como sujeitos pertencentes a contextos menos flexíveis e pouco abertos a mudanças, atestando o caráter de reprodução de referências cristalizadas e associadas a padrões tradicionais de masculinidade - caracterizada nos trabalhos por uma forte hierarquia ou assimetria das relações sociais entre homens e mulheres e pela homofobia.

Tendo em vista os resultados dessa investigação, confirmase a pertinência de observações de Weller (2005:112), ao destacar 
o quanto a juventude tem sido "objeto de pouca atenção por parte dos estudos feministas no Brasil e em outros países", bem como de Elizalde (2006), no sentido de que o "mapa dominante" dos estudos de juventude revela uma desarticulada trajetória no que diz respeito a análises de gênero, impossibilitando o avanço de novos olhares $e$ formas de exploração sobre as práticas $e$ experiências juvenis. Além disso, ainda que apenas um grupo pequeno de dissertações e teses tenha se preocupado com a análise de feminilidades e, em menor proporção, com aspectos da masculinidade de jovens, é subjacente nesses trabalhos a hipótese de que homens e mulheres pobres apresentariam uma menor disposição para relações mais igualitárias e constituição de novas identificações, assentadas na flexibilização e diversificação de condutas e apoiadas numa progressiva ideia de "escolha pessoal". Entretanto, nos perguntamos se as trajetórias de jovens pobres não sofreram também substantivas transformações capazes de impactar suas percepções e significados sobre a masculinidade.

Em estudo de caráter exploratório concluído em 2009, realizado com jovens negros e oriundos de famílias pobres da cidade de São Paulo, problematizamos essa perspectiva a partir da constatação de nuanças nos sentidos e significados atribuídos por rapazes quando incitados a falar sobre o tema. Ainda que tivessem características semelhantes do ponto de vista socioeconômico, foi possível identificar variações no modo como valoravam aspectos referentes aos relacionamentos afetivo-sexuais $e$ articulavam ideias sobre as diferenças e semelhanças entre homens/homens, mulheres/homens, mulheres/mulheres, heterossexuais/homossexuais, brancos/negros etc., bem como variações na forma como situavam suas experiências do presente e projetos futuros.

A investigação foi realizada com um grupo de 14 rapazes, com idades entre 18 e 25 anos, pobres ${ }^{1}$ e negros ${ }^{2}$. O trabalho de

1 A renda per capita mensal das famílias dos jovens variava entre $R \$ 350$ e $\mathrm{R} \$ 450$. Todavia, existiram variações no grupo, sendo a renda dos jovens 
Rapazes negros e socialização de gênero

campo, realizado entre junho de 2007 e julho de 2008, ocorreu em duas etapas. $\mathrm{Na}$ primeira, foram realizados três grupos de entrevistas coletivas, cuja diferenciação interna se deu com base na escolaridade obtida pelos jovens - ensino fundamental, ensino médio, ensino superior inconcluso. Num segundo momento, foram realizadas entrevistas individuais com três rapazes selecionados a partir da etapa anterior.

\section{Masculinidades: algumas referências teóricas}

Para compreender os repertórios, os significados e as ideias em circulação no imaginário de rapazes sobre masculinidade ou utilizando a categoria mais frequentemente empregada pelos entrevistados - sobre "ser homem", recorremos a uma literatura que problematiza as relações de gênero $e$ as subjetividades masculinas e femininas como resultantes de construções sociais, forjadas tanto a partir de interações - de homens/mulheres, homens/homens e mulheres/mulheres - quanto por dispositivos institucionais - discursos, leis, enunciados científicos, proposições filosóficas e morais -, que interferem nas subjetividades e nos atos cotidianos, corporais, sexuais e reprodutivos dos sujeitos (Medrado e Lyra, 2008). A categoria gênero é compreendida como uma chave analítica por meio da qual se torna possível entender o

universitários e com ensino médio concluído relativamente superior àquelas apresentadas pelos rapazes com ensino fundamental inconcluso.

2 Um primeiro desafio para a realização do estudo foi definir quem seriam os informantes, sobretudo considerando as singularidades do sistema de classificação racial brasileiro e a existência de um extenso vocabulário racial de um país onde a cor é usada como uma imagem figurada para raça (Guimarães, 2003; Rocha e Rosemberg, 2007). Essa dificuldade tornou-se mais evidente quando contatamos os rapazes. Embora tenha predominado aqueles que se declaravam negros, os jovens utilizaram também taxionomias como pardos, pretos e mulatos. Todavia, esses termos contêm associações raciais, embora sejam mais descritivas de uma aparência. Por isso, esses jovens foram considerados negros, estratégia largamente utilizada no trato de dados estatísticos, sem que essa orientação significasse a negligência às diferenças. 
conjunto de práticas, símbolos, representações, normas e valores sociais elaborados a partir da diferença sexual anatômicofisiológica percebida, diferença esta também construída no âmbito da cultura (Carvalho, 1999). Advoga-se, assim, que nenhuma experiência corporal existe fora dos processos sociais e históricos de construção de significados, ou seja, fora de relações sociais.

As variações de comportamento e atributos associados ao masculino e feminino constituem-se em elementos arbitrários, históricos e sociais, sendo a cultura a causa mais decisiva dessas diferenças. Trata-se de uma compreensão que busca desnaturalizar certas características atribuídas a homens $e$ mulheres e, comumente, traduzidas como essências e marcações masculinas e femininas. Assim, gênero pode ser entendido como "elemento constitutivo de relações sociais baseadas nas diferenças percebidas entre os sexos e, também uma forma primária de dar significado a relações de poder" (Scott, 1995: 86). Ao imbricar as relações sociais baseadas nas diferenças percebidas entre os sexos com as relações de poder, enfatiza-se que os usos e significados de gênero nascem de uma disputa política e são os meios pelos quais as relações de poder - de dominação e de subordinação - são construídas. Essa ênfase vem sendo historicamente problematizada por teóricas feministas, que partilham o esforço de apontar como, ao longo da história e em diferentes contextos, certas diferenças corpóreas foram eleitas para atestar acessos diferenciados a recursos materiais e simbólicos que, por sua vez, resultaram em relações desiguais de poder.

Nessa perspectiva, a masculinidade não pode ser vista como formulação cultural de um dado natural, mas como fruto de interações e de dispositivos institucionais para a conduta humana que, ao longo da história, nomearam diferenças corpóreas e forjaram assimetrias e hierarquias. A masculinidade é um conjunto de atributos que significam o masculino e, ao mesmo tempo, serve para marcar oposição e diferença ao feminino. Trata-se de uma posição nas relações de gênero que influencia as práticas $e$ a forma como o sujeito se relaciona com experiências físicas, 
Rapazes negros e socialização de gênero

pessoais e culturais. Entretanto, é preciso cuidado para pensar sobre a diferença sem cair imediatamente em dualismos feminino/masculino. Por isso, pareceu-nos útil o conceito de "masculinidade hegemônica", tal como vem sendo desenvolvido por Connell (1995, 1997) e Almeida (2000). Para a primeira autora $^{3}$, a masculinidade hegemônica é uma configuração de gênero que incorpora a resposta atualmente aceita para $\mathrm{o}$ problema da legitimação do patriarcado, garantindo a posição dominante dos homens e a subordinação das mulheres. Esse modelo não aceitaria a existência de masculinidades, mas de uma masculinidade devidamente viril (com as mulheres), dominante, provedora $e$, de preferência, branca. O segundo pesquisador afirma:

\begin{abstract}
Parece-me central o uso da noção de "masculinidade hegemônica", ou seja, não o "papel" masculino, mas sim uma variedade particular de masculinidade que subordina outras variedades. Se a fissura entre as categorias de "homem" e "mulher" é um dos fatos centrais do poder patriarcal e da sua dinâmica, no caso dos homens, a divisão crucial é entre masculinidade hegemônica e várias masculinidades subordinadas. Daqui segue-se que as masculinidades são construídas não só pelas relações de poder, mas também pela sua inter-relação com a divisão do trabalho e com os padrões de ligação emocional. Por isso, na empiria, se verifica que a forma culturalmente exaltada de masculinidade só corresponde às características de um pequeno número de homens (Almeida, 2000:149-150).
\end{abstract}

Para Almeida, a hegemonia se dá com a ascensão de determinados valores, vontades e práticas que passam a organizar a vida das pessoas nos mais diferentes âmbitos. Ela cria vontades, sensos comuns e se perpetua nos processos de socialização que,

3 Robert Connell submeteu-se à cirurgia para "mudança de sexo" $e$, mais recentemente, vem publicando ou reeditando suas produções com assinatura de Rayween (seu nome atual). 
sem obliterar alternativas, deixam-nas na semiescuridão. No caso do gênero, trata-se da capacidade de impor uma definição específica sobre masculinidade. $\mathrm{O}$ conceito permite uma concepção mais dinâmica de masculinidade, entendida como estrutura de relações sociais, em que várias masculinidades nãohegemônicas subsistem, ainda que reprimidas por um consenso sustentado pelos significados simbólicos incorporados. Assim, hegemônico e subalterno se conformam em uma ordem social e econômica desigual e dividida em gêneros. Aos homens, cuja ordem de gênero é mais privilegiada, as relações de poder que permeiam a construção da masculinidade podem parecer pouco visíveis, mas isso é diferente para aqueles que estão em situação de menor vantagem. No contexto brasileiro, por exemplo, podemos aventar sobre as implicações decorrentes dos intercruzamentos entre gênero, raça $e$ classe social para entendermos as relações que permeiam a constituição de masculinidades. Essa perspectiva, todavia, não implica numa "super simplificação" na qual os estudos sobre masculinidade acabariam por tipificar uma masculinidade negra e uma branca ou a existência de uma masculinidade trabalhadora e outra do empregador. Tais elementos servem, sobretudo, para atestar o caráter relacional de uma ordem de gênero, permeada por jogos de força, desequilíbrios e desigualdades (Arrilha, 2001).

\section{As percepções dos jovens: "ser homem" é...}

Nos diferentes grupos de entrevista constituídos para a pesquisa, os rapazes elaboraram depoimentos que permitiram constatar proximidades com dois paradigmas para articular ideias a respeito do tema masculinidade: a) a existência de fronteiras entre homens e mulheres; b) uma visão heterossexuada do mundo, na qual a sexualidade considerada "normal" e/ou "natural" está limitada às relações sexuais entre homens $e$ mulheres. Esse primeiro agrupamento não significou a constatação de que todos os participantes pensavam de maneira uniforme, 
Rapazes negros e socialização de gênero

mas, com frequencia, eles evocaram explicações que atestavam a existência de elementos que diferenciavam homens e mulheres $e$ de que a homossexualidade era, quando muito, definida $e$ admitida como "diferente".

Para um grupo maior de jovens - universitários e rapazes de ensino médio concluído - diferenças e singularidades que marcam a trajetória de homens/mulheres e de homens/homens se assentavam em um processo de socialização traçado num contexto e história particular. Para outro grupo de rapazes, notadamente aqueles que possuíam uma trajetória de menor escolarização, aspectos referentes às fronteiras e hierarquias de gênero se articulavam com elementos mais rígidos e "naturais", inscritos em aspectos fisiológicos e psíquicos que distinguiam os indivíduos segundo um sexo biológico.

No primeiro grupo, argumentos em torno do que é "ser homem" se estruturaram a partir da constatação de que existiam inúmeras agências por meio das quais foram adquirindo determinados significados, hábitos e práticas atribuídas à conduta masculina. Foi na família, na igreja, nas brincadeiras de crianças, no jogo de futebol, no grupo de amigos que aprenderam a dissociar homens e mulheres, buscar vínculo com determinados atributos associados à virilidade e reproduzir modelos sexuais, tanto pela forma de aproximação quanto pela forma de expressão do desejo (Welzer-Lang, 2001). Ao mesmo tempo, reconheceram a existência de algumas experiências por meio das quais foi possível certa inflexão e a constatação de que muitas transformações sociais têm operado mudanças na agenda de homens e mulheres.

No plano familiar, de maneira geral, os jovens percebiam seus pais como donatários de valores em que predominava uma forte hierarquia nas relações de gênero e uma divisão entre trabalho doméstico e trabalho produtivo, em que se destacavam os papéis de trabalhador/provedor/pai e cuidadora/mãe. Todavia, também reconheciam ambiguidades e fissuras nessa organização, tendo em vista que perdas e transformações de referências no espaço público forçaram suas famílias a construir novas dinâmicas 
no espaço privado. A precariedade do trabalho e o desemprego, o divórcio e/ou o falecimento de um dos membros adultos forçaram as famílias desses jovens a fazer ajustes que desarticularam configurações de acordo com posições, concepções e interações de cada um de seus membros.

Para jovens como Wagner ${ }^{4}$, estudante universitário, e Fabrício, que possuía ensino médio concluído, a experiência familiar, desde a infância, mostrava sinais claros de mudanças. $\mathrm{O}$ desemprego de seus pais, a retomada dos estudos e/ou inserção no mundo do trabalho de suas mães, a divisão de responsabilidades domésticas entre os irmãos e irmãs eram avaliados como exemplos de uma relativa inovação no domínio das relações sociais de gênero - com a participação de todos os membros adultos no trabalho assalariado, uma divisão mais igualitária do trabalho doméstico e de maior iniciativa profissional das mulheres, ainda que em nome de um projeto de mobilidade social da família ou de seus filhos. Por sua vez, Matheus, rapaz com ensino médio completo, considerava que a constatação das consequencias mais penosas que recaíram sobre sua mãe após o divórcio - buscar um trabalho sem experiência prévia, procurar uma nova casa, responsabilizar-se exclusivamente pela educação da filha e do filho - era um guia para que quisesse construir projetos futuros de união marcados por uma relação de poder menos acentuada. A família foi apresentada como um espaço socializador de diferenças e hierarquias de gênero, mas também figurou na fala dos rapazes como um laboratório, onde se elaboram, ainda que com configurações diferenciadas, novos percursos masculinos e femininos, por vezes redefinindo profundamente as relações de gênero (Cabanes, 2006; Sposito, 1993). Nesse processo, alguns jovens declararam desempenhar funções importantes na negociação dessas novas configurações,

\footnotetext{
4 Com o intuito de preservar a identidade dos jovens, optamos pelo uso de
} nomes fictícios. Essa estratégia foi previamente acordada com os entrevistados. 
Rapazes negros e socialização de gênero

mostrando uma evidente interferência dos mais novos no ordenamento da estrutura familiar.

Meu pai é super machista. Minha mãe voltou a estudar, mas teve a maior negociação lá em casa. Ele é muito tradicional, assim, de achar que mulher tem que ficar em casa. Eu e minha irmã, a gente pensa diferente e teve que apoiar minha mãe, porque se não ela não ia voltar [a estudar]. Ele [pai] só não implicou mais porque minha mãe é da igreja, tinha um lance de querer ler a Bíblia, então, ele acabou aceitando (Diogo, 19 anos, ensino médio concluído).

Estabelecendo comparações entre a vida de seus pais, todos migrantes e com níveis de escolaridade que não ultrapassavam o ensino fundamental $l^{5}$, esses rapazes reconheciam-se como sujeitos imersos num novo contexto. "Ser alguém na vida", como diziam para referir-se a um projeto futuro, demandava, tanto de homens quanto de mulheres, um alto investimento no estudo, a conquista de uma profissão e a construção de uma carreira, mais do que a constituição de uma família e de uma casa própria, que orientaram, na avaliação deles, a experiência paterna e materna. Diferentemente de outras gerações, segundo suas opiniões, moças e rapazes tinham pela primeira vez a possibilidade de construir trajetórias mais comuns em diferentes esferas e domínios sociais.

Essa ideia ganhava força, primeiramente, a partir do reconhecimento de que existia um fosso que distanciava a vida de seus avôs e pais e a deles. A esse respeito, foi comum a constatação de que a vida das mulheres mudou muito e, como decorrência, o lugar social ocupado por homens, bem como as respostas sobre o que é "ser homem" alteraram-se e sofreram deslocamentos. Como consequencia das mudanças que afetaram particularmente a agenda das mulheres, viam a perspectiva do projeto de um homem provedor em decadência e, para justificar

5 Apenas um jovem possuía mãe com ensino técnico de nível médio concluído (enfermagem). 
esse movimento, persistiram no argumento de que muitas mulheres jovens partilhavam com eles princípios mais horizontais de relacionamento conjugal e/ou afetivo. Foram os acontecimentos que levaram as mulheres a ter mais "informação" e sair do universo doméstico, que tornaram esse lugar social menos acessível.

Antes [no passado], a mulher se educava para ser dona de casa, mesmo que ela trabalhasse. Ela via o futuro dela ali: cuidando dos filhos. Hoje não! As meninas querem ter uma carreira, querem ter uma profissão. Tem mais meninas querendo fazer faculdade e eu acho que isso tem a ver com uma mudança de mentalidade e tal (Diogo, 19 anos, ensino médio concluído).

Falando do meu pai, acho que a gente é muito diferente, porque ele, na juventude dele, tinha outra ideia de projeto de vida. Entre a geração dele acho que tinha uma ligação entre trabalho e a vida, que o objetivo, um princípio da vida dele era trazer sustento para dentro de casa. A vida dele se resumia a isso. Acho que hoje a gente já vive diferente, pode realizar algumas coisas, de ter a opção de buscar alguma coisa aleatória para a vida (Fabrício, 25 anos, ensino médio concluído).

O argumento de Fabrício sobre a característica mais "aleatória" das trajetórias de vida, elemento que marcaria uma singularidade de sua geração, pode ser entendido como fruto de uma experiência urbana na qual os sujeitos se deparam com uma variedade de estilos de vida ${ }^{6}$, por meio das quais estabelecem uma relação de estranhamento, adesão e trânsito. Essa

6 Pode-se entender por estilo de vida um conjunto mais ou menos integrado de práticas que um indivíduo abraça, não só porque essas práticas preenchem necessidades utilitárias, mas porque dão forma material a uma narrativa particular de auto-identidade. Um estilo de vida implica um feixe de hábitos e orientações e, por isso, tem certa unidade de opções em um padrão mais ou menos ordenado (Giddens, 2002). 
Rapazes negros e socialização de gênero

argumentação ganha força quando consideramos o fato de que percebiam que, distintamente à experiência de seus pais, tinham mais oportunidades de acesso à escola, ao consumo $e$ ao lazer $e$ de que essa diferença estava vinculada à vida urbana $e$ à rede de serviços disponíveis na cidade, mesmo que de forma precária. A argumentação dos rapazes torna pertinente a análise de Sposito (1997), para quem as transformações decorrentes da urbanização, do acesso à escola e de alterações no mundo do trabalho modificaram os "modelos de instalação" e de passagem para a vida adulta, inclusive para os jovens mais pobres $e$ oriundos de familias trabalhadoras.

De fato, esse grupo de jovens tinha experiências bastante ampliadas de circulação por grupos e instituições $e$, como decorrência, não apenas percebiam-se como diferentes, mas reconheciam fazer parte de uma geração de sujeitos marcados pela diversidade. Quando falavam sobre as alterações nos modos de vida de moças e rapazes, os entrevistados não deixaram de estabelecer marcações como "os meus amigos", "os caras da rua", "os maloqueiros" e "os bregas", "nós" e "os outros". A sociabilidade e o consumo juvenil, bem como a maior ou menor adesão a alguns vínculos e valores institucionais da escola, da igreja, da família, de grupos juvenis, entre outros, despontaram como elementos que diferenciam trajetórias juvenis e a assunção de determinados hábitos. A emergência de novas estéticas, comportamentos e estilos de vida, a partir da convivência com outros jovens, a definição de grupos de amigos e práticas sociais foram capazes de forjar mudanças que diferenciam rapazes, construindo nuanças que, muitas vezes, resvalaram na definição de condutas masculinas. A adoção de determinados estilos de vida também torna pertinentes alguns "modelos" ou, pelo menos, um conjunto de práticas sociais e culturais comuns, que orientam suas condutas. Nessa perspectiva, a "aleatoriedade" das trajetórias juvenis se vinculava aos diferentes espaços de circulação, associação $e$ pertencimento que os rapazes construíram $e$ constroem. 
O que aconteceu comigo? (...) Chega uma hora que a maioria dos nossos amigos de infância, que moram na mesma rua, que moram há dois quarteirões de você, acabam deixando de ser seus amigos. Não é que você deixou de gostar, brigou e tal, mas é que as pessoas ficam diferentes. As diferenças que fazem você distanciar. (...) Se você curte uma arte, se você já trabalha, se você está na faculdade, tudo isso reflete na sua pessoa (Diogo, 19 anos, ensino médio concluído).

$\mathrm{Eu}$ acho que comecei a ficar diferente quando entrei pro teatro. As pessoas são completamente diferentes. São mais tolerantes com a homossexualidade, têm menos pudor com o corpo, essas coisas (...). Na quebrada, um cara tem vergonha de dar um beijo num homem, não pode. É só aperto de mão e um tapa nas costas, mas no teatro, você, homem ou mulher, acaba abrindo mão do preconceito (Hélio, 25 anos, estudante universitário).

Onde eu moro existe duas formas de você ser homem: ou você é brega ou você é maloqueiro. Ser brega é você ser mais família, se espelhar mais nos seus pais. É aquele cara que vai do trabalho para a escola, vai para a faculdade, tem seu grupinho de amigos que também faz a mesma coisa. É aquela galera que vai para a igreja. Ser maloqueiro é aquele jeito mais bagunçado, não é? É o lado mais da comunidade, que você fica mais com os amigos, fica na rua, joga o seu futebol, se tiver treta, ele está no grupo (...). Mas eu? Eu não sou nem um nem outro, eu estou no meio disso (Renato, 24 anos, ensino médio concluído).

Não devemos pensar, todavia, a movimentação desses sujeitos a partir de lógicas integradoras. Mais do que adesão a uma determinada fonte de orientação, foi possível identificar uma sociabilidade ambivalente, caracterizada por um jogo de distânciaproximidade entre diferentes direções. Por exemplo: a oposição entre "brega" e "maloqueiro" se apresentava menos como dicotomias para os jovens entrevistados e mais como escalas de 
Rapazes negros e socialização de gênero

comportamento. De maneira geral, os rapazes buscavam manter uma sociabilidade na rua - na qual, às vezes, falar mal das mulheres "galinhas", jogar futebol e consumir álcool garantia certa sociabilidade e circulação entre os pares - sem que, com isso, tivessem que abrir mão de determinadas orientações recebidas da família e noutras instituições ou grupos. Portanto, nessa dinâmica eles também não estavam desobrigados de demonstrar signos de domínio e de poder, manifestos na capacidade de mostrar desenvoltura nas experiências sexuais, na possibilidade de conquistar um patamar de consumo e na afirmação da heterossexualidade, reatualizando certo imaginário de masculinidade e suas conexões com relações assimétricas de poder.

No que diz respeito à homossexualidade, a argumentação dos jovens explicitou certa ambiguidade. A partir de propagandas governamentais, da inserção da temática em novelas, da manifestação pública de movimentos de defesa dos direitos civis, como a Parada do Orgulho LGBT, argumentavam em favor de modos menos cristalizados de reconhecer a sexualidade e de maior tolerância. Mas, reconhecer que homens podem "transar" com homens, inclusive com eles, e manter relações de amizade com homossexuais permaneciam como um tabu. A preocupação em "ser confundido" apontou a preeminência do gênero como organizador da apreensão acerca da homossexualidade masculina. Ainda que esses jovens tenham mais tolerância, a homossexualidade continuava representando uma intimidação para a identidade masculina desses rapazes, sendo forte a necessidade de esconjurar a ameaça de tal acusação, mesmo que reconheçam o caráter arbitrário de um sistema classificador $e$ hierarquizante.

Eu acho que eu tenho a cabeça mais aberta, mas eu vou falar a verdade. Às vezes, eu me pego no vacilo, participando de rodinhas com uns caras e falando mal de mina que pega um monte de cara, que está sendo tirada de 
galinha. Eu vejo que eu contribuo para o assunto. Então, eu acho que isso ainda persiste na minha cabeça (Diogo, 19 anos, ensino médio concluído).

Eu estava na Praça da República com os amigos da quebrada, a gente estava indo para a Galeria Olido, pra ver um show de rap. Aí, mano, apareceu a Jenniffer, que é uma travesti que eu conheci num trampo que eu fiz. Ela é gente boa pra caralho, mas aí, veio me cumprimentar. Eu parei, tipo, meu, estou fodido. Eu parei e falei com ela, mas já sabia. Foi ela virar as costas e os caras começaram a me alugar. Entendeu? (Matheus, 24 anos, ensino médio concluído).

Em que pese a constatação de determinadas permanências e de uma constante mediação sobre o modo de se comportar de acordo com diferentes espaços e públicos, as discussões realizadas, tanto no grupo de jovens universitários quanto com aqueles que tinham concluído o ensino médio, se deram por meio de argumentações que atestavam certo processo de familiarização de determinados ideais de masculinidade e caráter social $e$ relacional para a permanência e mutação dessas referências. Esse caminho discursivo foi diferente entre os jovens que não tinham concluído o ensino fundamental, entre os quais predominou a ênfase de argumentos que atribuíam a homens e mulheres uma identidade, um caráter distintivo, fundamentado em diferenças biológicas e psíquicas. Homens eram naturalmente mais fortes, brutos e ativos, enquanto mulheres eram, em essência, mais frágeis, afetivas e cuidadosas.

Tendo em vista essas polaridades, as transformações que afetaram a vida de mulheres e homens foram percebidas a partir de características e consequencias mais negativas e como resultantes de um declínio de valores estruturados em torno da vida familiar. A sociedade estaria, para eles, vivendo um período de declínio moral, perdendo referências como o "respeito", traduzido como valores que estruturavam a cumplicidade $e$ lealdade de relacionamentos estáveis, como o namoro e o 
Rapazes negros e socialização de gênero

casamento, bem como elementos que garantiriam fronteiras mais explícitas sobre o comportamento feminino e masculino. A emergência de identidades homossexuais, por exemplo, configurou-se como oriunda dessa crise, bem como a hipererotização das relações entre os jovens. Homossexuais eram descritos como "doentes", na maioria de suas observações, como possuídos pelo "demônio" - menção realizada em tom de ironia ou como subproduto de uma desordem social - especialmente no que diz respeito à aparição de jovens lésbicas. As manifestações do sexo, cantado nas letras - de estilos musicais como o funk e o axé, permeadas por metáforas e alegorias sobre o encontro sexual - e simulado por moças e rapazes em boates e danceterias seriam comprovações dessa mudança comportamental, que afetaria a vida de homens e mulheres, particularmente das jovens, que não mais se importariam com o jogo no qual compete a elas garantir, por meio da negação e/ou negociação do intercurso sexual, a preservação do "respeito".

Os jovens de menor escolaridade estruturaram argumentos que tenderam a naturalizar a pulsão masculina por sexo, enquanto que ao universo feminino eram imputadas características de maior controle. Quando tratavam de comportamentos femininos que rompiam com esse padrão, portanto, avaliados como ilegítimos, não lhe era atribuída a mesma contingência que orientava a conduta sexual masculina, mas sim a vocação feminina para buscar vínculos com os rapazes, mesmo que de forma despudorada. Noutra argumentação, as mudanças no comportamento sexual das jovens resultariam de uma situação de desequilíbrio psíquico, oriundo de frustrações afetivas desencadeadas por rapazes.

As meninas de hoje já curtem funk, já é mais... Se quiser ir para o baile... a menina aparece de minissaia. $\mathrm{Na}$ [boate] Coreto, as minas que estão com a menor minissaia não pagam para entrar. Acontece muito dessas coisas, 
entendeu? Eles promovem a prostituição (Ricardo, 19 anos, estudante do ensino fundamental).

Muitas vezes, os caras não querem saber de nada com a mina. A mina se ilude, entendeu? Aí, o cara dá um pé na bunda dela e ela fica iludida da vida. Acaba ficando descrente, não quer nada com ninguém, fica com trauma. O problema é que ela fica errada, não é não? (Adilson, 19 anos, estudante do ensino fundamental).

Antigamente se um homem arrumasse uma mulher, ela ia se dedicar para ele. Hoje não é mais isso. Você tem dúvidas... Está muito ruim do jeito que está. Sei lá! O mundo mudou demais mesmo. Acho que é isso que está acontecendo. Eu não sei o que passa na cabeça das meninas para fazerem isso, mas está muito... mudou tudo, tudo... (Denílson, 23 anos, estudante do ensino fundamental).

Outro elemento comum tratado por esse grupo dizia respeito às consequencias nocivas da desestruturação do mundo do trabalho assalariado, tendo em vista que a dificuldade em conquistar trabalho era um desafio para obtenção de rendimentos, mas também a principal causa para um processo de desestruturação familiar. Nesse aspecto, é importante enfatizar que, assim como os jovens de maior escolaridade, esses rapazes também possuíam famílias que enfrentaram processos substanciais de reestruturação, decorrentes do desemprego do pai $e$ da assunção de algumas responsabilidades como a manutenção dos rendimentos familiares por parte de suas mães. No caso de Denílson, por exemplo, esse processo se deu com contornos mais trágicos e permeados pela violência urbana: seu pai, desempregado e alcoólatra, foi assassinado no meio da via pública, quando ele ainda era criança.

Todavia, para esse jovem, assim como para seus colegas de grupo, eram as responsabilidades atribuídas ao homem no interior da família, associadas à figura do provedor de teto e sustento, capaz de exercer sua autoridade a partir de um bom caráter e boa moral, que convertiam as dificuldades enfrentadas em processos 
Rapazes negros e socialização de gênero

de luta por sobrevivência e superação. Em sua narrativa, a nova união da mãe, com um homem religioso e trabalhador, era o principal ingrediente para a "normalidade" e rearticulação das bases materiais e simbólicas que organizavam seu núcleo familiar. Para os demais, o restabelecimento do emprego paterno e a "ajuda" deles e das mães, com a entrada no mercado informal, possuíam o mesmo valor apaziguador dos conflitos $e$ desequilíbrios.

A partir de seus comentários e falas, foi possível compreender que a divisão do trabalho e os papéis no seio da família, embora fragilmente organizados, ainda eram inteiramente tradicionais e permaneciam reivindicados como um ideal. Nenhuma contestação por parte de suas mães foi manifesta, pelo contrário, estas emergiram como sujeitos que encontravam alguma compensação no prazer de organização doméstica e da proximidade com os filhos. Nesse sentido, os esquemas de percurso paterno foram reproduzidos sob as mesmas formas sociais e com a mesma divisão do trabalho doméstico na geração seguinte. Eles foram postos à prova, mas não fracassaram como experiências socializadoras desses rapazes (Cabanes, 2006).

Tornar-se chefe de família constituía-se em um projeto para esses jovens, muito embora percebessem a juventude como um momento de "curtição", e não de "responsabilidade" característica atribuída àqueles que já tinham filhos e família para prover. Entretanto, a fruição da condição juvenil e os projetos futuros se apresentavam como desafio decorrente do desemprego. ${ }^{7}$ As avaliações de Denílson e Adilson sobre as

\footnotetext{
7 Os três rapazes encontravam-se desempregados, diferentemente dos demais entrevistados, entre os quais predominavam sujeitos com remuneração própria com trabalho formal, informal e/ou estágio. Nenhum dos três entrevistados com ensino fundamental inconcluso possuía experiência anterior de trabalho formal e com registro em carteira. Experiências remuneradas de trabalho eram episódicas e, sobretudo, decorrentes de relações estabelecidas no bairro, em oficinas mecânicas, lava-rápido de carros, lojas de conveniência, feiras-livres.
} 
diferenças entre sua situação de vida e a experiência de homens de uma geração anterior foram sintomáticas. Os jovens afirmaram:

Acho que homem tem que ter emprego. O cara sem emprego não é nada... Constituir uma família $e$ ter seus filhos (...). Antes a coisa era melhor. O homem tinha seu pedacinho de terra, tinha tudo que precisava para alimentar a família dele. Tinha tudo, não tinha essa violência, essa pilantragem que tem hoje. As pessoas eram mais honestas, não tinha tanta maldade (Adílson, 19 anos, estudante do ensino fundamental).

A vida deles foi muito diferente da nossa. Eu acho que naquele tempo eles não tinham muito tempo. Eles trabalhavam na roça e não tinha muito tempo para pensar, que nem a gente tem hoje. Mas a gente hoje não tem no que pensar, porque não tem emprego (Denílson, 23 anos, estudante do ensino fundamental).

Por um lado, nesse grupo de rapazes o passado agrário e rural foi tratado como um momento idílico em que os lugares sociais de homens e mulheres estavam mais bem equacionados. Isso porque o trabalho produtivo, central para a constituição de uma masculinidade "responsável", mesmo sem prover homens de grandes fortunas, mantinha preservado o lugar social do homem. Para esse grupo, o declínio do trabalho remunerado, em especial o desalento em conquistar um emprego, privava-os das referências fundamentais de uma identidade social almejada: a do trabalhador/provedor/pai de família.

Por outro, como Abramo (1994) e Corrochano (2008) têm enfatizado, há de fato centralidade do mundo do trabalho para a garantia de sobrevivência e possibilidade de fruição do tempo de lazer, de estudo e de experimentação para jovens pobres. Denílson enfatizou a dimensão do "tempo para pensar" como uma conquista, ou seja, diferentemente daqueles de outra geração, em tese, tinha mais tempo para refletir, mas como operálo se não havia trabalho? A vida urbana oferecia poucas 
Rapazes negros e socialização de gênero

possibilidades para eles, sendo o principal entrave para acessá-la o desemprego. Não por acaso, foi entre esses jovens que o retrato de sua geração, em especial no que diz respeito aos jovens, era bem mais nebulosa do que a dos demais entrevistados. Num contexto de poucas oportunidades, os rapazes eram basicamente identificados como aqueles que estão na "correria" das drogas $e$ das ações criminosas e aqueles que estão na "correria" do trabalho ou na busca dele.

\section{Semelhanças e diferenças: classe social e raça}

Outras dimensões e marcadores também se apresentaram como relevantes para compreender certas noções sobre "ser homem". A primeira diz respeito a um intercruzamento comum aos grupos de rapazes entre a classe social e a pertinência de determinados atributos, como disposição para a "luta" $e$ a "guerra". A segunda, tratada de maneira menos uniforme pelos entrevistados, consistiu no reconhecimento de singularidades oriundas do fato de serem negros.

O pertencimento de classe e o lugar social ocupado por esses rapazes emergiram para marcar um caráter distintivo de suas experiências. Viver num contexto de pobreza, em bairros populares distantes do centro e partilhando dificuldades para acessar educação, trabalho e outros direitos sociais foram levantados pelos rapazes como elementos comprobatórios de que não só viviam num contexto bastante adverso para forjar trajetórias positivas, mas também como características que faziam deles "vencedores". Tal característica, na fala dos rapazes, se dava, sobretudo, porque percebiam-se como sujeitos capazes (ou necessitados) de construir disposições para superar uma condição socioeconômica menos favorável, também porque não tinham experimentado uma vida "fácil" que atribuíam àqueles jovens oriundos de camadas mais privilegiadas da sociedade.

Independentemente do perfil escolar ou de trajetórias dos jovens participantes dos grupos de entrevista, os rapazes viam-se 
como "guerreiros", pois tinham em comum o fato de serem da "periferia" e conseguirem encontrar mecanismos para continuar realizando planos e projetos. Mais do que isso, viam-se como sujeitos que mais vezes tiveram que comprovar suas qualidades, em oposição àqueles "jovens de classe média", que possuem "tudo de mão beijada" e eram "filhinhos de papai". Assim, conseguir sobreviver e resistir às adversidades de seu contexto social eram dados que demonstravam serem eles, quando comparados aos sujeitos de outros grupos socioeconômicos, detentores de determinadas características como a disposição $e$ determinação para a guerra do dia a dia.

Eu acho que a gente que está aqui, que conseguiu entrar numa faculdade já é um vencedor, porque a universidade não foi feita para a gente que é pobre, que é da periferia. Tipo, a gente teve que ralar muito para estar nesse lugar, porque ninguém dá isso de "mão beijada". O cara que é branco, que é de classe média, que é playboy, que vive na Vila Madalena não tem problema de entrar na faculdade, mas a gente que é do gueto tem, porque isso não é pra gente (Hélio, 25 anos, estudante universitário).

Na periferia, você tem que ser um guerreiro, um lutador. Todo cara é Mike Tyson porque tem que vencer uma guerra de cada vez, tem que ser um cara de responsabilidade, independente da escolha que ele faz. Isso eu acho que é comum entre todos os jovens que moram na periferia, se ele é ladrão, se é traficante, se é trabalhador, se é estudante, você pode ver, você vai falar com uma pá de cara $e$ todos eles vão se ver como lutadores, porque eles ganham uma batalha de cada vez para estar no lugar em que ele está, nada é fácil, de "mão beijada" que nem os playboys da vida (Renato, 24 anos, ensino médio concluído).

Em semelhança aos estudos realizados por Almeida (2000), podemos agrupar, a partir da argumentação dos rapazes, pares de oposição como guerreiros/filhinhos de papai, lutadores pobres/ricos apáticos, os que fazem por merecer/os que têm tudo 
Rapazes negros e socialização de gênero

de "mão beijada", que podem ser compreendidos como um universo semântico de expressões da masculinidade. Ao falar sobre suas experiências como jovens pobres e articular oposições com a trajetória de jovens de melhor condição socioeconômica, os jovens elencaram princípios classificatórios que articulavam um contínuo de significados acerca do que pensam sobre "ser homem", em consonância ao lugar ocupado por eles numa ou noutra ponta da escala. Nesse sentido, se por um lado ser pobre referia-se à necessidade de ocupar um lugar de menor privilégio $e$ poder, por outro, os desígnios e esforços realizados por eles invertiam, pelo menos do ponto de vista simbólico, essa relação.

$\mathrm{O}$ acesso dos jovens entrevistados ao poder - entendido como capacidade para controlar autonomamente as condições de sua existência - era limitado: tinham/tiveram dificuldades para garantir a continuidade da educação formal, precisavam trabalhar desde muito cedo ou estavam em busca de trabalho, tinham obstáculos para circular por espaços de lazer e consumir. Mas, articulando classe social $e$ determinadas atribuições atreladas à masculinidade $e$ à virilidade, tentavam reequacionar essa condição. Ter controle sobre seus destinos e construir um olhar que nomeava suas experiências como de um "guerreiro" era forma de reconhecerem-se como superiores aos "playboys". Assim, se a oposição entre ricos e pobres é, conforme Dayrell (2005), referência principal das camadas populares a respeito da desigualdade social, ela também serviu para que rapazes operassem uma inversão, pelo menos do ponto de vista semântico, dessa desigualdade. São os rapazes pobres os guerreiros e lutadores, os ativos de um campo de batalha.

Para alguns jovens, as diferenças entre classes sociais eram traduzidas também como diferenças entre negros e brancos. Para um grupo de rapazes, foi comum, por exemplo, a sobreposição de categorias, como "nós pobres e negros", ou então, oposições do tipo "nós negros e eles ricos", como que traduzindo as desigualdades entre ricos e pobres também para o plano das desigualdades raciais. Contudo, a pertinência da questão racial, 
do ponto de vista da argumentação dos rapazes, figurou como elemento importante, sobretudo para aqueles que tinham uma forte identificação com movimentos e grupos juvenis para os quais ser negro era algo constitutivo de uma identidade coletiva. Também se evidenciou como relevante para aqueles que se reconheciam como imersos em espaços e ambientes percebidos como de frequencia predominantemente branca - como faculdades de "elite" e/ou postos de trabalho de maior remuneração e qualificação profissional - $e$ viam na afirmação de uma negritude a possibilidade de trânsito e circulação positiva.

Três rapazes entrevistados eram pertencentes ou exintegrantes de grupos juvenis de hip hop. Entre eles foi possível perceber narrativas semelhantes às descritas por Weller (2004) que, ao se debruçar sobre a experiência de jovens envolvidos com esses coletivos culturais, constata um processo de conscientização e mudança na forma de pensar, do qual emerge uma forte identificação com aspectos relativos à negritude, ou a ser negro, $e$ que não se associa essencialmente a aspectos fenotípicos, mas, sobretudo, a um processo denominado por ela como "tornar-se negro". Para esses rapazes, ser negro e/ou preto era sinônimo das experiências comuns de marginalização e de luta contra o racismo, bem como a cor da resistência política. Os bairros pobres em que residiam eram denominados "gueto" e "novo quilombo" e caracterizados como um território onde eles e seus pares dos coletivos eram comparados a figuras históricas como o líder quilombola Zumbi dos Palmares.

Eu acho que a favela é o novo quilombo, é onde está toda a pobreza e a miséria que a gente tem hoje em São Paulo. É onde mora a pobreza, é onde o ônibus, o navio negreiro de São Paulo, vai buscar as mulheres negras, que são empregadas domésticas, e os negros, que estão desempregados. Nós que estamos no hip hop somos os novos guerreiros, os quilombolas, a gente se arma de música para protestar, para fazer as coisas acontecerem (Renato, 24 anos, ensino médio concluído). 
Rapazes negros e socialização de gênero

Mais uma vez a figura do "guerreiro" foi ressaltada por esses jovens, mas agora como efeito reativo a uma condição de subalternização racial e como elemento para demarcar uma alteridade frente ao homem branco. Para tanto, foram evocados elementos comuns encontrados na história de resistência à escravidão, segregação e discriminação e que tinham correspondência com uma possibilidade de construir uma autoimagem que rejeitava o lugar de submissão, pelo contrário, apontava para um ethos não-cordial e insubmisso. Além disso, do ponto de vista objetivo, ser integrante de coletivos de hip hop impactava, segundo esses rapazes, a assunção de novas orientações no plano afetivo-sexual (a busca por relacionamentos exclusivamente com mulheres negras), a avaliação sobre as vivências masculinas de outros jovens dos bairros pobres, mais comprometidas com projetos de ascensão social via consumo e/ou adequação dos signos daquilo que reconhecem como do poder branco.

O cara põe aquela camisa rosinha bebê, com etiqueta da Lacoste, sai com o carro dele todo equipado, todo bombando, com a corrente de ouro, todo metido a playboy, essas coisas... Só que ele é parado pela polícia, porque o neguinho esquece que ele não é moreninho, que ele é neguinho, que, para a polícia, neguinho vestido desse jeito, todo equipado, é bandido (Renato, 24 anos, ensino médio concluído).

E tinha também a ideia de que só mulher branca era bonita. Eu não conseguia ver uma trança, uma raiz de uma mulher preta como algo bonito. Estou falando a verdade pra vocês, eu queria mudar como? Saindo de onde eu vivia, deixando de ser periférico, ficando com uma loira $e$ me enquadrando. Foi o hip hop que mudou minha cabeça, que mudou minha mente, minha forma de pensar. Daí eu fui vendo que tudo isso era imposição, entendeu? Fui resgatando minhas origens africanas, minha ancestralidade, entendeu? (Matheus, 24 anos, ensino médio concluído). 
Entre outros rapazes, todavia, as chaves para compreender a argumentação em torno de uma articulação entre masculinidade $e$ negritude foram o trânsito $e$ a mobilidade (e não a oposição). Isso porque eles, notadamente alguns universitários, avaliavam como importante para suas experiências a assunção da negritude como uma possibilidade de transpor fronteiras, circular $e$ estabelecer trocas em novos espaços (educativos, culturais, laborais e de lazer) e com jovens de outras origens sociais. Para esses rapazes, as exibições públicas de certos modelos estéticos e corporais se apresentaram como possibilidades de conformar um modo positivo de hetero-identificação, reequacionando, inclusive, aspectos de menor prestígio como suas condições de jovens pobres e moradores de bairros distantes do centro.

A mobilidade e circulação pela cidade foram ressaltadas, por um lado, em seus aspectos mais positivos, como tomar contato com universidades, com circuitos culturais e de lazer e com pessoas que destoavam daquelas de seus bairros de origem, por outro, também como situações provocadoras da premência de novas referências especialmente sobre si, mas também sobre como demarcar alteridade. Esses jovens passaram a adotar estilos de roupas e, especialmente, modos de arrumar o cabelo - uso de cabelos longos, trançados e black-power - para marcar uma distinção $e$ pertencimento racial nos seus trânsitos pela cidade $e$ por diferentes grupos com os quais tinham contato, sem que isso implicasse na associação a um grupo e/ou cultura específica. Tratava-se de formas mais estetizadas e performativas de assunção da negritude, manipuladas por esses rapazes como possibilidades de se tornarem mais interessantes, sedutores e bonitos.

É, tipo assim, eu acho que essa coisa de se assumir como negro, de usar uns panos diferentes, de usar o cabelo diferente, foi importante, porque eu acho que na faculdade, todo mundo passou a me olhar diferente. Eu não sou mais o bolsista pobre, esfarrapado, que não tem nada, que eles estão fazendo o favor de me aceitar. Tem uma coisa de 
Rapazes negros e socialização de gênero

interesse agora. Quem é esse cara? Qual é a dele? (Marcos, 20 anos, estudante universitário).

Isso também vai deixando a gente muito limitado. Eu sou negro, não escondo de ninguém, tipo, cuido do meu cabelo, não deixo ninguém levar uma comigo, mas acho que se não tomar cuidado, você acaba sendo condenado a viver como as pessoas acham que o negro tem que viver. Tem amigos na minha faculdade que se eu chegar $e$ chamar todo mundo para ir a uma rave, vão dizer que eu sou louco, que negócio de negro é samba, black e pagode (Anderson, 20 anos, estudante universitário).

A experiência desses jovens aponta para sua capacidade de fazer uso de um corpo simbólico, estabelecendo mediações no espaço e nos diferentes contextos sociais. Acena também para a possibilidade de que a diferença impressa em seus corpos, pela cor da pele e pelos demais sinais fenotípicos (nariz, boca e tipo de cabelo), comumente no contexto brasileiro associados a padrões de "fealdade" (Gomes, 2002:42), converterem-se em marcadores importantes para construção de subjetividades de homens negros $e$ adoção de novos estilos corporais como signos políticos, da moda, de vida e de beleza. Todavia, em acordo com Sansone (2007), essa assunção deve ser compreendida como fruto da experiência singular de jovens que têm uma trajetória de exploração de estilos de vida e de diferentes regiões da cidade, cujas fronteiras geográficas e simbólicas vão além de sua própria comunidade e que conformaram redes sociais mais variadas $e$ multifacetadas.

Os jovens de menor instrução, por exemplo, tenderam a refutar oposições fundamentadas em diferenças e desigualdades raciais. Essa diferença pode ser entendida no bojo dos modos como manipulavam as próprias formas de classificação, recorrendo, mais do que os outros jovens, a taxionomias mais diversas à polaridade entre negros e brancos. Eram mais predominantes na argumentação desse grupo elementos que distinguiam sujeitos do sexo masculino de diferentes classes 
sociais, situação na qual esses rapazes percebiam-se, sobretudo, como premidos pelo desafio de seguir a vida em um contexto adverso. Era essa experiência que forjava traços constitutivos de singularidades.

\section{Socialização de gênero}

A construção da masculinidade deve ser entendida como uma experiência coletiva $e$ individual em constante transformação. Nessa perspectiva, compreender a conformação de sentidos $e$ significados atribuídos por jovens sobre o que é a masculinidade implica no reconhecimento de que é possível verificar, mesmo num grupo aparentemente uniforme, variações de valores, ainda que permeadas por certos traços comuns fundamentados por um ideal de masculinidade hegemônica. No trabalho realizado, aspectos referentes à distinção homem/mulher e heterossexual/homossexual emergiram como estruturantes para que rapazes discorressem sobre aquilo que denominavam como "ser homem". Entretanto, foi possível identificar nuanças no conjunto de argumentações utilizadas pelos diferentes sujeitos da pesquisa. Para alguns, tais marcadores eram artefatos sociais, para outros, estes estavam inscritos na natureza dos indivíduos, distinguiam homens e mulheres, sendo variações entendidas como desvio. Semelhanças também foram constatadas, por exemplo, as oposições entre jovens ricos e pobres, traduzidos na contraposição entre "playboys" e "guerreiros", que marcaram referências de alteridade e juízos de valor a respeito da idealizada proteção que o dinheiro dos pais desses jovens bem-nascidos lhes proporciona. Essa oposição marcava uma hierarquia de classe, mas também uma inversão dessa relação de poder no plano da masculinidade: negavam aos "playboys" a condição de "guerreiros" devido à incapacidade de lutar pela vida. Para alguns jovens essa oposição também se constituía numa hierarquia racial, que acenava para desigualdades materiais e simbólicas entre brancos e negros. 
Rapazes negros e socialização de gênero

Tendo em vista a proposta metodológica dos grupos de entrevista, estruturados com base nos níveis de escolaridade obtidos pelos sujeitos, uma primeira hipótese formulada era a de que a escolarização contribuía para o delineamento de determinadas compreensões sobre as relações de gênero e sobre a conformação de valores a respeito da masculinidade. Todavia, sem negar a importância de trajetórias mais longas de escolarização e do acesso a determinados saberes socializados na instituição escolar para a conformação de valores, chama a atenção o fato de que no percurso da pesquisa os jovens entrevistados acenaram, sobretudo, para experiências vivenciadas no âmbito da família, da relação com os pares de amigos/as e nos relacionamentos afetivo-sexuais e na circulação por diferentes espaços sociais. Em primeiro lugar, foi possível perceber que as transformações das últimas décadas nos planos do trabalho e do emprego forçaram as famílias pobres a se adequar no plano privado aos novos modelos de organização da vida pública. Problemas aparentemente comuns mobilizaram, para algumas famílias, profundas transformações, ou pelo menos novas disposições, nas relações de gênero e na divisão do trabalho, impactando as expectativas e subjetividades das novas gerações. Ao mesmo tempo, para outras, os processos adaptativos se assentaram na reafirmação de determinados lugares sociais de homens e mulheres, influenciando igualmente a educação de seus filhos.

Assim, as diferenças na socialização ${ }^{8}$ familiar dos jovens puderam ser entendidas a partir de lógicas de reprodução, mas também de inovação. Jovens universitários, por exemplo, relataram certas expectativas de seus pais para que estudassem. Por sua vez, a premência de "trabalhar para ser alguém" era uma perspectiva mais enfatizada pelos jovens de menor escolaridade, sobretudo porque, de fato, suas bases econômicas e outros

8 A socialização é entendida como o processo mediante o qual os sujeitos produzem sua experiência, evidenciando uma equação na qual os indivíduos se constroem e ao mesmo tempo são construídos socialmente. 
suportes (bolsas de estudo, apoio dos pais, trabalho remunerado) eram mais frágeis do que os daqueles que frequentavam o ensino superior. De toda forma, foram mais comuns nos depoimentos dos rapazes as tentativas conflituosas de equilibrar essas duas lógicas. Sendo jovens pobres, por um lado, a continuidade dos estudos na maioria das vezes demandava trabalho remunerado $e$, por outro, pais e mães evocavam valores contraditórios: "vai trabalhar porque você já é homem!" ou "aqui em casa é tudo igual: homem lava a roupa, mulher tem que trabalhar". O antagonismo dessas orientações, todavia, dependia, de certa forma, de suportes como creche, escola, emprego formal (deles ou dos pais). Na família deles, o "tamanho do cobertor" definia também as possibilidades de projetos e idealizações futuras. Por isso, a assunção individual de novos modelos de identidades sociais e de gênero não é suficiente para a conformação de novas masculinidades. Torna-se igualmente necessário um conjunto de mudanças de natureza mais ampla: é preciso transformar o direito, as instituições, os serviços públicos, as organizações de modo a repercutir em várias instâncias da vida pessoal e coletiva, incluindo a esfera doméstica.

Um segundo aspecto a chamar atenção nas entrevistas é a importância dos grupos de amigos e colegas com os quais, ao longo do percurso de suas vidas, os jovens vão se identificando $e$ firmando alteridades. Esse processo foi importante para entender, por exemplo, a constituição de certas conexões entre a adoção de determinados estilos juvenis, entre masculinidade e classe social $e$ entre masculinidade e raça. A esse respeito, a sociologia da juventude tem tomado a sociabilidade juvenil como uma importante esfera de socialização de moças e rapazes (Dayrell, 2005; Corti e Souza, 2004), ressaltando o espaço privilegiado de práticas, representações, símbolos e rituais, no qual jovens buscam experimentar circuitos $e$ trocas, ampliam relações $e$ ganham visibilidade por meio dos mais diferentes estilos. Trata-se de uma experiência bastante importante caso se compreenda que, por um lado, os sujeitos se encontram num período da vida relevante de 
Rapazes negros e socialização de gênero

expansão em relação ao mundo social, à sua crescente capacidade de analisar situações, hierarquizar problemas, fazer escolhas. Por outro, se for posto em relevo que os processos de socialização contemporâneos vêm se dando a partir de novas lógicas, nas quais sujeitos e instituições não são mais redutíveis a um programa coerente e único, a um papel e a uma programação, tal como era pensada a socialização na sociedade industrial (Dubet, 2006; Pais, 2007).

As sociedades modernas não conseguem mais realizar de maneira igual e relativamente exitosa uma função básica $e$ antropológica que todas as sociedades têm de realizar, ou seja, geração, comunicação e preservação de sentido, como puderam fazê-lo outras ordenações sociais do passado. Apesar de as sociedades modernas terem desenvolvido ou permitido o desenvolvimento de instituições especializadas de produção e comunicação de sentido, não estão mais em condições de comunicar ou preservar ordens supraordenadas de sentido e valor, obrigatórias em geral (Berger e Lukman, 2004:80).

Reconhecer essas mudanças não implica atestar que os sujeitos estariam sitiados pela angústia ou fadados a construir de maneira solitária sua existência. Tampouco, no caso da socialização de gênero, perfilhar da premissa de que há uma crise instalada e de que inexistem parâmetros e constrangimentos para a ação de sujeitos, segundo determinantes e orientações sociais sobre o comportamento de homens e mulheres. Segundo Berger e Luckman, na sociedade contemporânea os sujeitos orientariam seu agir e sua conduta conforme valores que imperam naquilo que denominam como comunidade de vida: o grupo mais próximo de relação diária dos sujeitos, com o qual partilham, ainda que de maneira parcial, certos pontos de apoio para suas experiências e ações cotidianas. É assim, portanto, que se torna possível entender as diferenças biográficas individuais $e$ a 
emergência de novos significados partilhados, ainda que por um grupo determinado.

Essa experiência é particularmente importante quando consideramos os jovens, uma vez que, nessa etapa da vida, os sujeitos são capazes de abrir outros espaços, nos quais o grupo de pares, o estilo ao qual aderem e o consumo dos meios de comunicação de massa vão cada vez mais se constituindo como parâmetros de avaliação e organização das relações interativas com a realidade externa. Esse jovem tem acesso a múltiplas referências culturais, constituindo um conjunto heterogêneo de redes de significado que são articuladas e adquirem sentido na sua ação cotidiana. Assim, ele interpreta a sua posição social, dá um sentido ao conjunto das experiências que vivencia, faz escolhas $e$ age na sua realidade.

É verdade que a diversificação dos costumes e das relações de gênero no Brasil tem por fundamento um substrato relacional $e$ hierarquizado da vida social. Essa constatação, todavia, não implica em referendar hipóteses de que as possibilidades de flexibilização dos costumes estejam acessíveis apenas a determinados grupos ou classes mais prósperos. As experiências desses jovens nos permitem a constatação de que divisões de classe e outras linhas fundamentais de desigualdade são elementos importantes para compreender o acesso diferenciado a formas de realização pessoal e de acesso a poder - dimensão produtora de diferença, exclusão e marginalização. Atestam também que os rapazes construíram-se e foram construídos como sujeitos numa complexidade de espaços e de tempos, que permitiram o acesso a certa multiplicidade de valores, relações $e$ experiências de socialização importantes para a construção de um imaginário sobre o que é "ser homem".

\section{Referências bibliográficas}

ABRAmo, Helena. Cenas juvenis: punks e darks no espetáculo urbano. São Paulo, Scritta, 1994. 
Rapazes negros e socialização de gênero

AlmEIDA, Miguel Vale de. Senhores de si: uma interpretação antropológica da masculinidade. Lisboa, Fim do Século, 2000.

ARRILHA, Margareth. Homens: entre a "zoeira" e a "responsabilidade". In: ARRILHA, Margareth et alii. Homens e masculinidades: outras palauras. São Paulo, ECOS/Ed. 34, 1998, pp.51-78.

BERGER, Peter; KELLNER, Hansfried. Le mariage et la construction de la réalité. In: BERGER, Peter; THOMAS, Luckmann. La construction sociale de la realité. Paris, Armand Colin, 2006, pp.307-334.

; LUCKMAN, Thomas. Modernidade, pluralismo e crise de sentido: a orientação do homem moderno. Petrópolis, Vozes, 2004.

CABANES, Robert. Espaço privado e espaço público: o jogo de suas relações. In: TELLES, Vera da Silva et alli. Nas tramas da cidade: trajetórias urbanas e seus territórios. São Paulo, Associação Editorial Humanitas, 2006, pp.389-432.

CARVAlHO, Marília Pinto de. No coração da sala de aula: gênero $e$ trabalho docente nas séries iniciais. São Paulo, Xamã, 1999.

; SOUZA, Raquel; OlIVEIRA, Elisabete Regina Baptista de. Jovens, sexualidade e gênero. In: SPOSITO, Marilia Pontes. (coord.) O estado da arte sobre juventude na pós-graduação brasileira: Educação, Ciências Sociais e Serviço Social (1999-2006). Belo Horizonte, Argumentvm, 2009, pp.229-274.

CONNEL, Robert. La organización social de la masculinidad. In: VALDES, Teresa; OlaVARRíA, José. (orgs.) Masculinidades: poder y crisis. Santiago, ISIS-FLACSO/Ediciones de lãs Mujeres, 1997, pp.31-48.

Políticas da masculinidade. Educação \& Realidade, n 20 , Porto Alegre, 1995, pp.185-206.

CORROCHANO, Maria Carla. O trabalho e sua ausência: narrativas de jovens do Programa Bolsa Trabalho no município de São Paulo. Tese de Doutorado, Faculdade de Educação, USP, 2008.

CORTI, Ana Paula; SouZA, Raquel. Diálogos com o mundo juvenil: subsídios para educadores. São Paulo, Ação Educativa, 2004. 
DAYRELL, Juarez. A música entra em cena: o rap e o funk na socialização da juventude. Belo Horizonte, Editora da UFMG, 2005.

O rap e o funk na socialização da juventude. Educação $e$ Pesquisa, vol. 28, n 1, São Paulo, 2002, pp.117-136.

DUBET, François. El declive de la institución: profesiones, sujetos e indivíduos en la modernidade. Barcelona, Editora Gedisa, 2006.

ELIZALDE, Silvia. El androcentrismo en los estudios de juventud: efectos ideológicos y aperturas posibles. Ultima década, vol. 14, $\mathrm{n}^{\circ} 25$, Santiago, 2006, pp.91-110.

GIDDENS, Anthony. Modernidade e identidade. Rio de Janeiro, Jorge Zahar, 2002.

GOMES, Nilma Lino. Trajetórias escolares, corpo negro e cabelo crespo: reprodução de estereótipos ou ressignificação cultura? Revista Brasileira de Educação, n 21, Rio de Janeiro, 2002, pp.40-51.

GuimARÃES, Antônio Sérgio Alfredo. Como trabalhar com "raça" em sociologia. Educação e Pesquisa, vol. 29, n 1, São Paulo, 2003, pp.93-107.

HeIlborn, Maria Luiza; CABRAL, Cristiane S. e BozÓN, Michel. Valores sobre a sexualidade e elenco de práticas: tensões entre modernização diferencial e lógicas tradicionais. In: HEILBORN, M. L. et alii. O aprendizado da sexualidade: reprodução e trajetórias sociais de jovens brasileiros. Rio de Janeiro, Garamond/Fiocruz, 2006, pp.212-265.

MartuCCElli, Danilo. Cambio de rumbo: la sociedad a escala del individuo. Santiago, LOM Ediciones, 2007.

MEDRADO, Benedito; LYRA, Jorge. Por uma matriz feminista de gênero para os estudos sobre homens e masculinidades. Revista Estudos Feministas, vol. 16, n 3, Florianópolis, 2008, pp.809-840.

PAIS, José Machado. Cotidiano e reflexividade. Educação \& Sociedade, vol. 28, nº 98, Campinas, 2007, pp.23-46.

PERALVA, Angelina. O jovem como modelo cultural. Juventude e contemporaneidade. Revista Brasileira de Educação, nº 5/6, São Paulo, 1997, pp.25-36. 
Rapazes negros e socialização de gênero

RoCHA, Edmar José da; ROSEMBERG, Fúlvia. Autodeclaração de cor e/ou raça entre escolares paulistanos(as). Cadernos de Pesquisa, vol. 37, no 132, São Paulo, 2006, pp.759-799.

ScOTT, Joan. Gênero: uma categoria útil de análise histórica. Educação \& Realidade, vol. 20, n 2, Porto Alegre, 1995, pp.71-99.

SPOSITO, Marilia Pontes. A ilusão fecunda: a luta por educação nos movimentos populares. São Paulo: Hucitec, 1993.

. A pesquisa sobre jovens na pós-graduação: um balanço da produção discente em Educação, Serviço Social e Ciências Sociais (1999-2006). In: SPOSITO, M. P. (coord.) O estado da arte sobre juventude na pós-graduação brasileira: Educação, Ciências Sociais e Serviço Social (1999-2006). Belo Horizonte, Argumentvm, 2009, pp.17-56.

. Estudos sobre juventude em educação. Revista Brasileira de Educação, no 5/6, São Paulo, 1997, pp.37-52.

VIANNA, Cláudia Pereira e UnBEHAUM, Sandra. O gênero nas políticas públicas de educação no Brasil: 1988-2002. Cadernos de Pesquisa, vol. 34, n 121, 2004, pp.77-104.

WELLER, Wivian. A presença feminina nas (sub)culturas juvenis: a arte de se tornar visível. Revista Estudos Feministas, vol. 13, $\mathrm{n}^{\circ} 1$, Florianópolis, 2005, pp.107-126.

- O hip hop como possibilidade de inclusão e de enfrentamento da discriminação e da segregação na periferia de São Paulo. Caderno CRH, vol. 17, n 40, Salvador, 2004, pp.242-260.

WELZER-LANG, Daniel. A construção do masculino: dominação das mulheres e homofobia. Revista Estudos Feministas, vol. 9, n 2, 2001, Florianópolis, pp.460-482. 